\title{
Lessons from the pink ribbon
}

"T

am tired of your pink ribbons!" one of my leukemia doctors said half jokingly in a meeting. He is not alone. Some people think there is too much hype about October as the breast cancer awareness month. If there is one color, one disease, and one month that is clearly etched in public memory, is the pink ribbon and breast cancer awareness during the month of October. From grocery stores to National Football League teams, the message of breast cancer awareness during that month takes precedence. Is it too much to talk about one disease? Are we commercializing this message and perhaps detracting from the intended purpose? ${ }^{1}$

National breast cancer awareness month was started in 1985 by a partnership between American Cancer Society and AstraZeneca (then known as Imperial Chemical Industries). The initial focus was on screening for breast cancer and early detection of disease, and it has now evolved into a platform to "promote a national dialogue on breast cancer."

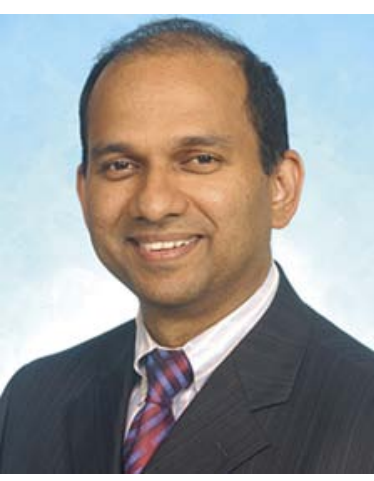

health care providers who strive each day to defeat this terrible disease. In memory of the loved ones we have lost and inspired by the resilience of those living with the disease, let us strengthen our resolve to lead our Nation toward a future free from cancer in all its forms. I encourage citizens, government agencies, private businesses, nonprofit organizations, and all other interested groups to join in activities that will increase awareness of what Americans can do to prevent breast cancer."

I don't dispute that the pink ribbon gets excessive exposure during the month October, but as a breast cancer doctor who cares for young and elderly patients with this devastating illness, how can I tell the 1.3 million women around the world, ${ }^{2}$ including the 232,340 women in the United States, who will be diagnosed in 2013 with breast cancer that they are getting undue attention during October? $?^{3}$ How can I explain this to the survivors of the half a million women worldwide $(39,620$ The story of the pink ribbon as the symbol of breast cancer is also interesting. Evelyn Lauder, an executive at Estee Lauder Inc, started the Breast Cancer Research Foundation in 1993 and together with a friend selected the pink ribbon as the foundation's symbol. But even before that, in 1991, the Susan G. Komen Foundation had given the pink ribbon to participants in a race in $\mathrm{New}$ York City for breast cancer survivors.

Breast cancer awareness month is now a global event. The plea for greater awareness of breast cancer, more research and the quest for a cure reached the White House in October 2012, when President Obama said in a proclamation, "This month, we stand with the mothers, daughters, sisters, aunts, and friends who have been affected by breast cancer, and we recognize the ongoing efforts of dedicated advocates, researchers, and

Commun Oncol 2013;10:277-278 DOI: 10.12788/j.cmonc.0067 (c) 2013 Frontline Medical Communications of those in the United States) ${ }^{3}$ who succumbed to the disease this year? $?^{3}$ How we can I tell those mothers, sisters, and daughters that they are getting too much attention?

As a result of this strong advocacy, breast cancer researchers received about $\$ 602.7$ million funding from the National Cancer Institute in 2012, whereas prostate cancer researchers received about \$265.1 million and lung cancer researchers, $\$ 314.6$ million. ${ }^{3}$ There's no disputing the fact that there is a huge difference in funding between breast cancer and other cancers. But because of that increased funding, we have a better understanding of the intricacies of breast cancer biology, the heterogeneity of the disease, and its genomic classification. Over the past 10 years that newly acquired knowledge has helped scientists develop therapies that are more targeted and that allow clinicians to prescribe more personalized and highly effective medicines for their breast cancer patients. These advances have improved patient quality of life, decreased the therapies' side effects, and decreased mortality. 


\section{From the Editor}

Other illnesses, including other cancers, should also be able to benefit from the advocacy efforts put together by breast cancer groups. The strong alliances forged between individual patients, their communities, nongovernmental organizations, and the private sector, with government functioning as a lightening rod has bolstered the fight against breast cancer. I applaud these efforts to keep the debate about a major illness alive, but we need more debates and a broader national dialogue on all major killers in our society, such as heart disease, cancer, infections, and even poverty.

Today's media coverage focuses heavily on the threat of terrorism, but if you look back over the last decade, the number of terror-related deaths in the United States would likely come in at fewer than $100,{ }^{4}$ whereas nearly 400,000 women died from breast cancer during that time. So let's talk about breast cancer during the month of October and flood the media and public conscience with awareness of the disease and its effects. Perhaps advocates for other diseases or even major societal afflictions could learn from the pink ribbon.

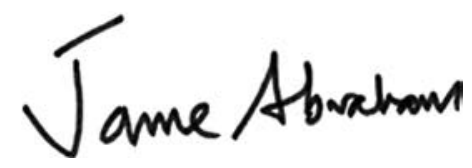

Jame Abraham, MD

References

1. Sulik GA. Pink ribbon blues: how breast cancer culture undermines women's health. New York: Oxford University Press. 2012.

2. Veltri L, Abraham J. Breast cancer as a global epidemic. Breast Cancer Manage. 2012;1:5-7.

3. National Cancer Insitute Web site. SEER Stat Fact Sheets: Breast. http://seer.cancer.gov/statfacts/html/breast.html. Updated 2013. Accessed September 4, 2013.

4. Friedersdorf $\mathrm{C}$. The irrationality of giving up this much liberty to fight terror. The Atlantic. http://www.theatlantic.com/politics/ archive/2013/06/the-irrationality-of-giving-up-this-much-libertyto-fight-terror/276695/. Posted June 10, 2013. Accessed September 4, 2013. 